\title{
Spatial variation in soft-sediment benthos
}

\author{
D. J. Morrisey, L. Howitt, A. J. Underwood, J. S. Stark \\ Institute of Marine Ecology, Zoology Building A08, University of Sydney, NSW 2006, Australia
}

\begin{abstract}
Variation (patchiness) in the distribution of organisms and other environmental variables exists at different spatial scales. This patchiness has important implications for comparative and descriptive studies of distribution and abundance because it complicates comparisons of abundance at the largest spatial scales. Although the existence of patchiness has been recognised for a long time, it has not been adequately addressed in most studies of marine soft sediments, which are often confounded (or 'pseudoreplicated') because of a lack of appropriate spatial replication. Spatial variation in the distribution of soft-sediment macrofauna in Botany Bay, Australia, is described using a nested, hierarchical sampling design. Significant variation was detected at spatial scales from $10 \mathrm{~m}$ to $3.5 \mathrm{~km}$. Implications of patchiness for environmental sampling and monitoring, and the means of overcoming associated problems, are discussed. The present study concerns the abundance of macrofauna, but the conclusions are general and are relevant to studies of other variables, such as pollutants
\end{abstract}

\section{INTRODUCTION}

The patchy distribution of benthic organisms in marine soft sediments has been recognised for a long time (Barry \& Dayton 1991, McIntosh 1991). The distributions of other sediment-related variables, such as pollutants (Krumgalz et al. 1989, Luoma \& Phillips 1988) and sediment particle-size (e.g. Stanley \& Swift 1976), are also likely to be heterogeneous.

Causes of patchiness in the distributions of benthic invertebrates have been examined in several studies. Physical environmental factors, such as water depth and movement and sediment type, are believed to determine large-scale patterns of distribution (e.g. Thorson 1957, Gray 1974, Warwick \& Davies 1977, Barry \& Dayton 1991). Within these patterns, however, spatial heterogeneity exists at various scales, forming a mosaic of patches. It has been suggested that heterogeneity is maintained by a variety of disturbances and other biotic and abiotic factors (Thrush et al. 1989, Barry \& Dayton 1991).

Studies of the distribution of fauna, pollutants and other variables in soft sediments often involve sampling at widely-spaced locations (for example, kilometres or tens of kilometres apart). Such studies include those concerned with monitoring for environmental impacts of human activities. A common practice in these surveys is to collect a number of replicate samples (or, in some cases, only one sample) at each of several locations or stations (e.g. Swartz et al. 1986, Eleftheriou \& Basford 1989, Hornung et al. 1989, Duineveld et al. 1990, Newell et al. 1991; see review in Butman 1987). There are, however, important problems of interpretation of the data arising from this practice.

The spatial scales of patchiness in the variables being measured are not often known before sampling is done. Consequently, patchiness at any spatial scales between that of the sampling units (small scale) and the locations sampled (large scale) will not be revealed by the sampling design. The within-location variation has not been adequately estimated by the replicate samples, preventing valid comparisons among locations (the data are 'pseudoreplicated': Hurlbert 1984).

The bigger the difference of scale between one level of sampling (e.g. replicate grab samples) and the next (e.g. locations), the bigger will be the possible range of scales of patchiness that will be interposed. Examples where comparisons between locations several kilometres apart are made on the basis of replicate samples collected at only one place in each location are given by Pearson (1975), Botton (1979) and Swartz et al. (1986). Examples at a smaller scale (hundreds of metres) are given by Larsen (1979) and Newell et al. (1991). 
The problem of confounding discussed above can be overcome by the use of nested sampling designs (Green \& Hobson 1970, Green 1979, Underwood 1981. Andrew \& Mapstone 1987). Each of a series of successively smaller spatial scales is nested within the scale above. This provides an estimate of the contribution of each scale to the total variation among samples within the largest scale of comparison. Partitioning of the variances associated with each scale, using analysis of variance (Underwood 1981), permits unconfounded comparisons among mean abundances of organisms (or other variables) at any of the chosen scales.

Here we examine variation in the fauna of soft sediments at a range of spatial scales, using a nested sampling design. The study was done in Botany Bay, New South Wales, Australia. Very few studies of the fauna in soft sediments have been done using sampling designs capable of unravelling the confounded patterns of abundance at different spatial scales (notable exceptions are Green \& Hobson 1970. Phillips \& Fleeger 1985, Jones et al. 1990). This account therefore demonstrates the importance of nested designs, with appropriate replication at each scale, in studies of the distribution of variables such as abundances of organisms and concentrations of pollutants. It also illustrates the consequences of inadequate sampling designs to the interpretation of differences in abundance at large spatial scales in heterogeneous environments.

\section{METHODS}

Sampling design. The design incorporated 5 spatial scales (Fig. 1b), ranging from $1 \mathrm{~m}$ between replicate samples to $3.5 \mathrm{~km}$ between the 2 sides of Botany Bay. The largest scale represents the sort of distance at which areas are sampled in many published studies of distribution and environmental impact. Replication at this distance $(3.5 \mathrm{~km})$ within each side of the bay was not possible in Botany Bay, but this should be considered in other studies. Instead, replicate locations (A, B and C, D in Fig. 1) were spaced at $1 \mathrm{~km}$ apart on each side of the bay.

Use of these replicate locations allows unconfounded comparisons of the 2 sides of the bay. For example, consider the situation with a single control area and a single putatively disturbed area $3.5 \mathrm{~km}$ away from it (such as an area with chemical contamination). These are to be sampled to detect any influence of contaminants and sampling is done in a relatively small part of each area. If there are significantly large differences in abundance from any one location to any other at, say, a distance of $1 \mathrm{~km}$ apart, any differences between the 2 areas (control and contaminated) may

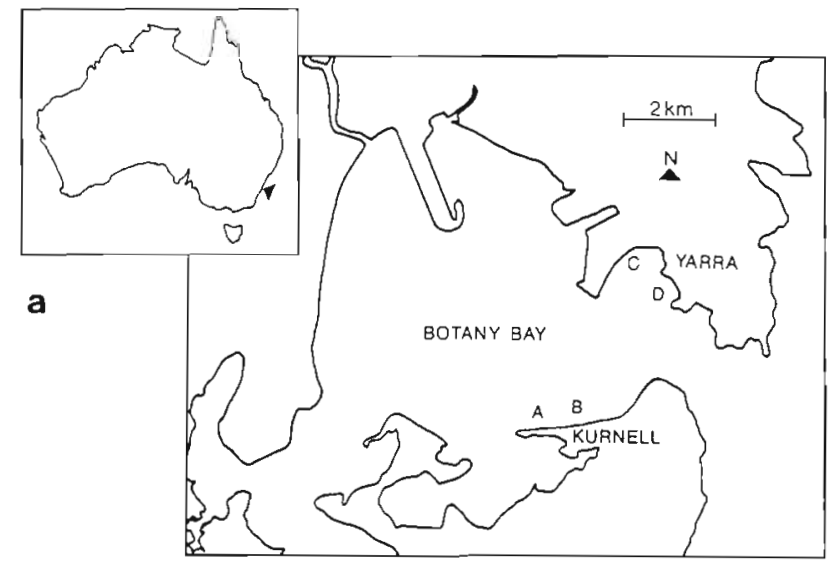

b

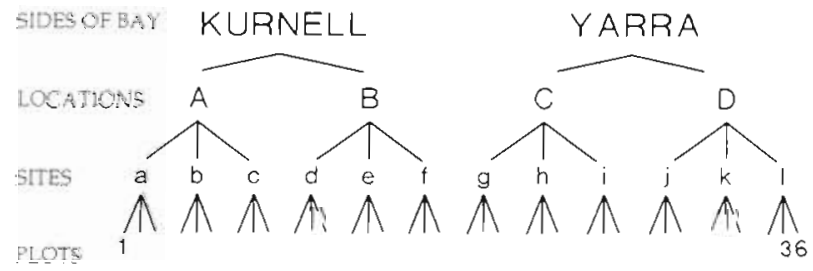

Fig. 1 (a) Botany Bay showing locations sampled: Kurnell A and $B$, Yarra $C$ and $D$. Water depth at all locations was $6 \mathrm{~m}$. (b) Hierarchical sampling design used in the study. Three Plots were nested within each of 3 Sites (represented here by lower-case letters), nested within each of 2 Locations (upper-case letters), nested within each Side of the Bay. Three replicate cores were collected at each Plot

simply reflect the fact that they are different localities - not that one is contaminated. To detect effects of contaminants, sampling must demonstrate more difference between the contaminated and control areas than is found from location to location within them. There are other problems with this example (Underwood 1991a) because of the lack of replication, but this is not the topic addressed here.

It is typical of published accounts of sampling organisms in sediments to take replicate samples within short distances of each other relative to the distance apart of the areas being sampled. This, of itself, creates a small scale of sampling within an area. Thus, samples taken a few metres or tens of metres apart in 2 locations $1 \mathrm{~km}$ apart are really only in a small patch in each location. Again, there may be variation in abundances of organisms from patch to patch that would confound any larger-scale differences from location to location.

To examine the potential need for sampling at different scales and to obtain data for cost-benefit analyses (Snedecor \& Cochran 1967, Underwood 1981, Kennelly \& Underwood 1984, 1985) for the design of future sam- 
pling programmes, 2 other scales (hundreds and tens of metres apart) were examined in the present study. In each Location, 3 Sites (areas ca $50 \mathrm{~m}$ in diameter) $100 \mathrm{~m}$ apart were randomly selected. In each Site, 3 replicate Plots (about $2 \mathrm{~m}$ in diameter) $10 \mathrm{~m}$ apart were randomly chosen. Finally, in each Plot, 3 replicate cores (see details below) were sampled, $1 \mathrm{~m}$ apart.

Sites and Plots were chosen to represent the spatial scale of replication in different published studies. Most studies would sample the equivalent of the 2 Sides of the Bay with individual replicate samples spaced at distances of hundreds of metres (i.e. Sites), tens of metres (i.e. Plots) or smaller distances apart.

Sampling methods. Samples were collected during 3 consecutive days in September 1990 by divers using plastic core tubes (10 cm diameter, $10 \mathrm{~cm}$ deep). Pilot tests had shown that the precision of the estimates of faunal numbers obtained with this size of core was acceptable $(\mathrm{SE} / \mathrm{mean}=0.1 ;$ Elliott 1977). Numbers of animals collected with $20 \mathrm{~cm}$ deep cores were no greater than with $10 \mathrm{~cm}$ deep cores, justifying the depth of core used. Samples were fixed with $7 \%$ formalin to prevent deterioration before extraction of the fauna. They were sieved through a $0.5 \mathrm{~mm}$ mesh. Identification of the fauna was to a relatively coarse level; families in the case of polychaetes, sub-orders or higher taxa for other groups. This level of resolution was appropriate given the great taxonomic uncertainty of many infaunal animals in southeastern Australia.
Eight of the taxa in the samples were chosen as being consistently present and representing different relative abundances (small, medium and large; Fig. 2). These, plus the total numbers of individual animals and the total numbers of taxa, were each analysed by 4 -factor nested analyses of variance. All factors (Side of Bay, Locations, Sites and Plots) were random. Homogeneity of variances was checked using Cochran's test and heterogeneity was removed by $\log (x+1)$ or $(x+1)^{05}$ transformations.

\section{RESULTS}

For the number of taxa, the number of individuals and the 8 separate taxa analysed, differences in mean abundance were observed at all of the spatial scales examined (Tables $1 \& 2$; Fig. 2). The pattern of differences at various spatial scales is not the same for each taxonomic group (Table 2). For example, whilst the mean number of polychaetes varied at spatial scales of Location, Site and Plot, the component families showed different patterns. Of the more abundant families, syllids were patchy in abundance at small spatial scales of 10 's and 100's of metres (i.e. among Plots and Sites) whereas numbers of spionids were significantly greater at Kurnell than at Yarra (km's apart) and no other spatial scales were significant. Sabellids were significantly variable at the scales of Locations and Plots.

Table 1. Summaries of analyses of variance for selected taxa

\begin{tabular}{|c|c|c|c|c|c|c|c|c|c|c|c|c|c|}
\hline \multirow{2}{*}{$\begin{array}{l}\text { Source of } \\
\text { variation }\end{array}$} & \multirow[t]{2}{*}{$\mathrm{df}$} & \multicolumn{3}{|c|}{ a. Total no. taxa } & \multicolumn{3}{|c|}{ b. Total individuals ${ }^{1}$} & \multicolumn{3}{|c|}{ c. Total polychaetes ${ }^{2}$} & \multicolumn{3}{|c|}{ d. Syllids ${ }^{2}$} \\
\hline & & Mean Sq. & $F$ & $\mathrm{p}$ & Mean Sq. & $F$ & $p$ & Mean Sq & $F$ & $\mathrm{p}$ & Mean Sq. & $F$ & $\mathrm{p}$ \\
\hline Sides of Bay & 1 & 389.12 & 0.54 & $>0.50$ & 2181.26 & 3.13 & $>0.20$ & 23.65 & 1.21 & $>0.30$ & 3.09 & 0.20 & $>0.65$ \\
\hline Location (S) & 2 & 722.46 & 11.45 & $<0.01$ & 697.44 & 2.95 & $>0.10$ & 19.52 & 6.30 & $<0.05$ & 15.41 & 3.37 & $>0.05$ \\
\hline Site (L(S)) & 8 & 63.12 & 2.39 & $<0.05$ & 236.63 & 3.05 & $<0.02$ & 3.10 & 4.12 & $<0.005$ & 4.57 & 8.37 & $<0.001$ \\
\hline Plot (Si(L(S))) & 24 & 26.37 & 3.61 & $<0.001$ & 77.69 & 6.60 & $<0.001$ & 0.75 & 5.15 & $<0.001$ & 0.55 & 2.57 & $<0.005$ \\
\hline Residual & 72 & 7.31 & & & 11.77 & & & 0.15 & & & 0.21 & & \\
\hline \multirow{2}{*}{$\begin{array}{l}\text { Source of } \\
\text { variation }\end{array}$} & \multirow[t]{2}{*}{$\mathrm{df}$} & \multicolumn{3}{|c|}{ e. Spionids } & \multicolumn{3}{|c|}{ f. Sabellids ${ }^{1}$} & \multicolumn{3}{|c|}{ g. Cirratulids ${ }^{2}$} & \multicolumn{3}{|c|}{ h. Amphipods ${ }^{1}$} \\
\hline & & Mean Sq & $F$ & $\mathrm{p}$ & Mean Sq. & $F$ & $\mathrm{p}$ & Mean Sq & $F$ & $\mathrm{p}$ & Mean Sq & $F$ & $p$ \\
\hline Sides of Bay & 1 & 14421.33 & 47.43 & $<0.05$ & 147.42 & 12.01 & $>0.05$ & 32.86 & 20.33 & $<0.05$ & 2821.49 & 9.63 & $>0.05$ \\
\hline Location (S) & 2 & 304.07 & 0.80 & $>0.40$ & 12.28 & 14.76 & $<0.005$ & 1.62 & 2.19 & $>0.10$ & 292.94 & 1.92 & $>0.20$ \\
\hline Site (L/S)) & 8 & 379.96 & 1.95 & $>0.05$ & 0.83 & 2.30 & $>0.05$ & 0.74 & 5.57 & $<0.001$ & 152.36 & 2.54 & $<0.05$ \\
\hline Plot (Si(L(S))) & 24 & 194.51 & 1.56 & $>0.05$ & 0.36 & 2.05 & $<0.05$ & 0.13 & 0.52 & $>0.90$ & 59.96 & 5.49 & $<0.001$ \\
\hline Residual & 72 & 124.93 & & & 0.18 & & & 0.26 & & & 10.92 & & \\
\hline \multirow{2}{*}{$\begin{array}{l}\text { Source of } \\
\text { variation }\end{array}$} & \multirow[t]{2}{*}{ df } & \multicolumn{3}{|c|}{ i. Caprellids ${ }^{2}$} & \multicolumn{3}{|c|}{ j. Bivalves } & & & & & & \\
\hline & & Mean Sq. & $F$ & $\mathrm{p}$ & Mean Sq. & $F$ & $\mathrm{p}$ & & & & & & \\
\hline Sides of Bay & 1 & 29.33 & 0.82 & $>0.45$ & 8.33 & 0.07 & $>0.80$ & & & & & & \\
\hline Location (S) & 2 & 35.75 & 8.66 & $<0.01$ & 124.81 & 7.02 & $<0.05$ & & & & & & \\
\hline Site $(L(S))$ & 8 & 4.13 & 4.36 & $<0.005$ & 17.77 & 2.01 & $>0.05$ & \multirow{3}{*}{\multicolumn{6}{|c|}{$\begin{array}{l}{ }^{1} \text { Data transformed to }(x+1)^{0.5} \text { before analysis } \\
{ }^{2} \log (x+1) \text { transform }\end{array}$}} \\
\hline Plot (Si(L(S))) & 24 & 0.95 & 2.63 & $<0.001$ & 8.84 & 1.81 & $<0.05$ & & & & & & \\
\hline Residual & 72 & 0.36 & & & 4.90 & & & & & & & & \\
\hline
\end{tabular}


Table 2. Results from the spatial variation study in Botany Bay. Spatial scales at which significant variation exists among replicates are shown. - : differences not significant; - significant differences $(p<0.05)$

\begin{tabular}{|c|c|c|c|c|}
\hline \multirow[t]{2}{*}{ Taxon } & \multicolumn{4}{|c|}{ Spatial scale } \\
\hline & Sides of Bay & Location & Site & Plot \\
\hline Total no. taxa & - & • & * & - \\
\hline Total no. individuals & - & - & * & - \\
\hline \multicolumn{5}{|l|}{ Large abundance: } \\
\hline Polychaetes & - & - & • & - \\
\hline Amphipods & - & - & • & • \\
\hline \multicolumn{5}{|l|}{ Medium abundance: } \\
\hline Syllids & - & - & • & - \\
\hline Spionids & • & - & - & - \\
\hline Sabellids & - & * & - & $*$ \\
\hline Caprellids & - & * & * & * \\
\hline \multicolumn{5}{|l|}{ Small abundance: } \\
\hline Cirratulids & - & - & * & - \\
\hline Bivalves & - & - & - & * \\
\hline
\end{tabular}

There were more significant differences at the smaller spatial scales of Sites ( 7 of the 10 analyses) and Plots ( 8 out of 10 ) than at the larger spatial scales of Locations (5 out of 10 ) and Sides of Bay ( 2 out of 10 ).
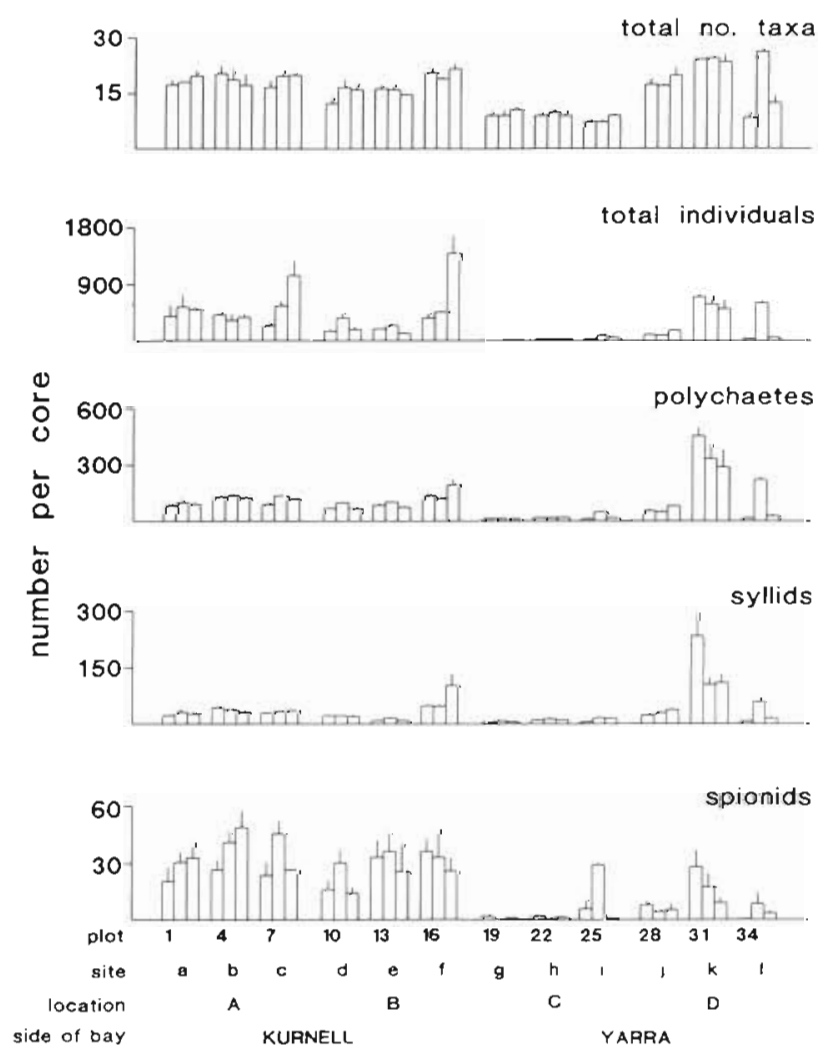

These spatial scales were not, however, equally important in terms of the magnitude of the variations observed.

The contribution of each spatial scale to the total variance was calculated for each of the taxa analysed (Table 3). Interpretation of variance components is not straightforward and should be done with caution (Underwood \& Petraitis 1991). For example, the size of the residual variance in the analysis of variance for each taxon will affect the sizes of the contributions of the different spatial scales to the total variance. In the present study, the proportion of the total variance contributed by the residual variances differed among the different taxa by a factor of 4 (10 to $45 \%$; Table 3$)$. This makes it difficult to compare the relative importance of different spatial scales across taxa. The components of variance do, however, indicate that there is considerable residual (i.e. within-Plot) variation for most taxa. This suggests that patchiness exists at smaller spatial scales than Plots.

The variance components also confirm the relative importance of the Sites scale in the distribution of syllids and the Sides of Bay scale for spionids, sabellids and cirratulids. They indicate, too, that in some instances certain scales are important even though they were not detected as being significant by the analysis
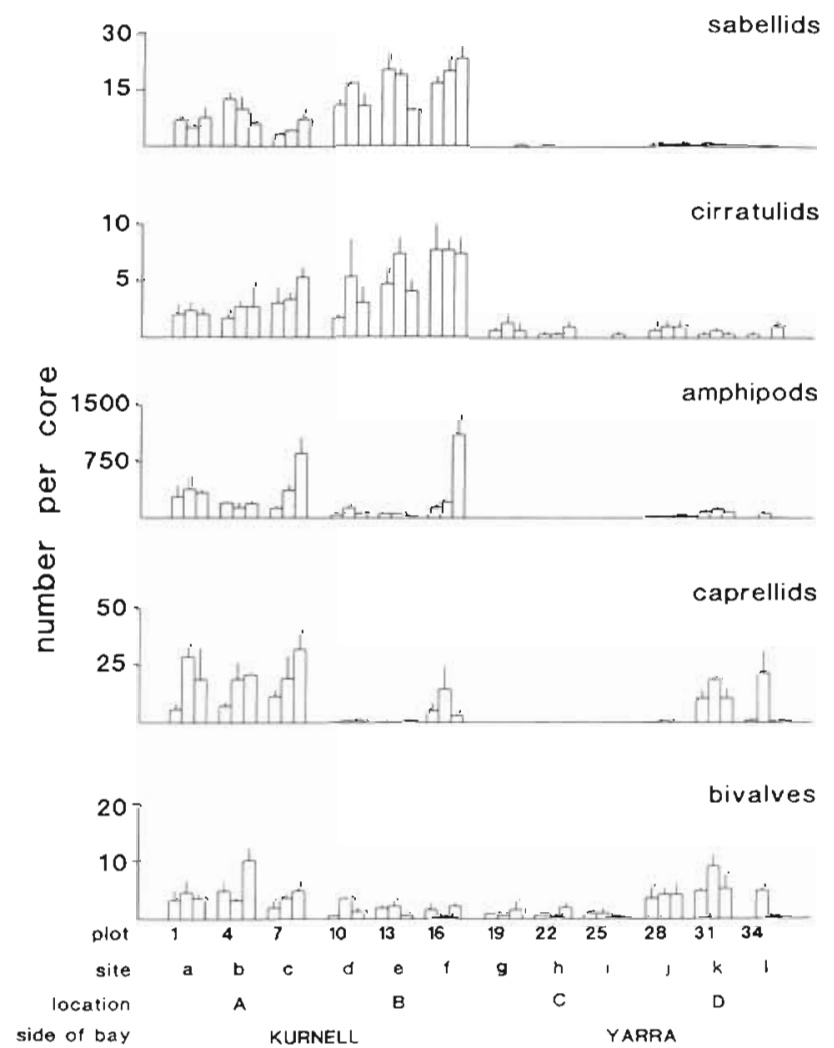

Fig. 2. Mean ( \pm SE) numbers of taxa or animals per core $(n=3)$ in each Plot. There are 3 Plots in each of 3 Sites in each of 2 Locations in each Side of the Bay. The category 'amphipods' excludes caprellids, which are shown separately 
Table 3. Variance estimates derived from the analyses of variance for selected taxa (calculated from untransformed data according to Underwood 1981; negative estimates are assumed to be zero)

\begin{tabular}{|c|c|c|c|c|c|c|c|c|c|c|}
\hline $\begin{array}{l}\text { Source of } \\
\text { variation }\end{array}$ & $\begin{array}{c}\text { Total } \\
\text { no.taxa }\end{array}$ & $\begin{array}{c}\text { Total } \\
\text { no. ind. }\end{array}$ & Polychaetes & Syllids & Spionids & Sabellids & Cirratulids & Amphipods & Caprellids & Bivalves \\
\hline Sides of Bay & 0 & 25035 & 0 & 0 & 261 & 55 & 5 & 26539 & 0 & 0 \\
\hline Location (S) & 24 & 6508 & 3240 & 394 & 0 & 20 & 1 & 0 & 65 & 4 \\
\hline Site (L(S)) & 4 & 25059 & 6501 & 1236 & 21 & 3 & 1 & 7710 & 2 & 1 \\
\hline Plot (Si(L(S))) & 6 & 43095 & 1394 & 414 & 23 & 3 & 0 & 31011 & 22 & 1 \\
\hline Residual & 7 & 26130 & 1882 & 590 & 125 & 9 & 4 & 17124 & 61 & 5 \\
\hline
\end{tabular}

of variance. For example, the apparent difference between Sides of Bay for sabellid polychaetes in Fig. 2 was not significant in the analysis of variance. This is likely to be due to the significant difference among Locations within Sides of Bay and the consequent very small power of the test for the difference between Sides of Bay ( 1 and 2 degrees of freedom). The power is, in fact, 0.34, with probability of Type I error set at $p=0.05$. Comparison of the variance components shows the component for Sides of Bay to be relatively large (Table 3). Similarly, the large differences among Plots in the mean numbers of amphipods obscures the importance of variation at larger spatial scales. Again, the large variance component for Sides of Bay indicates that the differences across the Bay were not detected because of the lack of power.

The object of this study was to examine variances at different spatial scales, rather than means associated with the particular areas sampled (hence the random choice of these areas). Some consistent patterns do, however, emerge from consideration of the means and variances. As discussed below, such patterns may provide useful pointers for future work. For example, at Location D, Yarra Bay, Site $\mathrm{k}$ had greater numbers of individuals in all 5 comparisons among Sites at this Location where differences were significant (shown by SNK tests on mean number of taxa, total numbers of individuals, total numbers of polychaetes, syllids and caprellids; Fig. 2, Table 2). These differences corresponded with the presence of tubebuilding chaetopterid polychaetes at Site k, as discussed below.

\section{DISCUSSION}

This study shows that abundances of infauna in soft sediments are patchy at a range of spatial scales, from a metre up to several kilometres. It is also, of course, possible that such heterogeneity exists at scales less than $1 \mathrm{~m}$. Volckaert (1987), using spatial autocorrelation analyses, detected patchiness in the distribution of polychaetes in soft sediments at scales of $<10 \mathrm{~cm}$, 10 to $50 \mathrm{~cm}$ and $>50 \mathrm{~cm}$. Thrush $(1986 \mathrm{a}, \mathrm{b})$ described the effects on benthic communities of the pit-digging activities of crabs and of decomposing accumulations of seaweed. Both of these disturbances operated at scales of less than a metre.

Factors influencing spatial heterogeneity in the distribution of soft-sediment macrofauna have been mentioned in the 'Introduction'. In a recent review, Barry \& Dayton (1991) consider large-scale (both spatial and temporal) abiotic factors as defining broad patterns of distribution. Within these patterns, other processes operate continually at smaller temporal and spatial scales to modify distributions and abundances. These smaller-scale factors may be biotic, abiotic or involve interactions between the two (Thrush 1991). Many will operate at a range of scales, not necessarily by the same process at each scale.

Patterns of variation in studies such as the present one may provide pointers to the mechanisms causing the observed variation. An example from our study has been mentioned above. The larger numbers of taxa and of individuals of several taxa at Site $\mathrm{k}$ compared with Sites $\mathrm{j}$ and $\mathrm{l}$ at Location D, Yarra, coincided with the presence of patches, up to several metres in diameter, of the tubes of chaetopterid polychaetes Mesochaetopterus sagittarius (unpubl. data). Chaetopterids were also present at Yarra D, Site 1, Plot 35, and again this coincided with greater numbers of individuals of various other taxa compared with the other plots at this site. Several other taxa, such as tanaids and eunicid polychaetes, were more abundant at these sites. This observation raises the possibility that the presence of the tubes is in some way facilitating the presence of the other animals.

The present findings have important consequences for studies of the distribution of organisms in soft sediments, including those concerned with environmental monitoring. The spacing among replicates in such studies is generally of the order of a few metres, partly depending on method of collection. With remote sampling methods, such as grabs, the actual distance is likely to be unknown and will vary with such factors as water depth and water movement. Levels of the measured variables in these replicates are, of course, 
intended to be representative of levels over the Iocation as a whole. The locations themselves are usually spaced at distances ranging up to several kilometres. Any spatial variation at levels between that of the spacing of samples and the spacing of locations will be compounded into the variation among locations in the statistical comparison of locations. Scales of variation smaller than the spacing of replicate samples will be incorporated into estimates of variation among locations and among samples within each location. Thus, such smaller-scale variations in mean abundances of organisms will not cause errors in identification of differences among locations. They will, however, lead to loss of power in tests for such differences. This loss of power will be particularly acute in situations where organisms are distributed differently in different patches within each location, giving rise to large variation about the mean of each location.

The problem of confounding is particularly pertinent in studies where distributions of animals, pollutants or other variables are extrapolated from means of replicate samples to whole locations for purposes of comparison. A common example would be for the purpose of mapping distributions. As an example of such confounding, consider the data from the present study concerning the distribution of numbers of polychaetes (Fig. 2). These data showed no significant difference between the 2 sides of the bay. Had sampling been done only at the scales of Sides of the Bay and replicate cores $1 \mathrm{~m}$ or so apart, comparisons between the 2 sides would be spatially confounded. They might suggest, for example, that polychaete numbers were larger at Yarra than at Kurnell, no different, or smaller, depending on whether the replicate cores from Yarra had, by chance, been collected from Plot 31, Plot 35 or Plot 34 respectively. The size of the variances of sample means may give rise to caution in this respect, assuming that replicate samples have been collected. Spacing of replicates may, however, be such that all happen to lie within one of several different patches within the location. In this case, among-replicate variance will be small even though within-location variance is large.

Comparisons for the same location over time (e.g. Buchanan et al. 1974, 1978, Probert 1981, Buchanan \& Moore 1986, Swartz et al. 1986, Josefson 1987. Shillabeer \& Tapp 1989) are also likely to be confounded by small-scale spatial variation, because the samples will not necessarily come from the same type of patch at each time of sampling (because softsediment sampling is invariably destructive and, in the case of remote sampling, because of inaccuracy in positioning the sampler).

The problems associated with the spatial scales of sampling can be overcome by using the kind of nested design described here. The scales can be chosen arbitrarily and adapted to the objectives of the particular study. Given the often large costs of collecting and sorting samples, it is usually appropriate to do a pilot study to identify scales at which variation is significant.

Spatial autocorrelation has been used to examine patterns of distribution (Jumars et al. 1977, Volckaert 1987, McArdle \& Blackwell 1989, Thrush et al. 1989). This technique allows description of small-scale spatial patterns, larger-scale studies being impractical because of the large numbers of samples required. It is not, therefore, an alternative to the nested sampling design used here for the identification of ranges of spatial scales of variation. The nested design has an important practical advantage over autocorrelation. As mentioned, the nested design permits cost-benefit analyses to be done and the results to be applied to subsequent sampling. In studies of impacts, costbenefit and power analyses will be relevant to the design of sampling to detect what are considered, a priori, to be biologically or environmentally significant changes in the fauna (see references in Underwood 1981, Kennelly \& Underwood 1984, 1985). One of the aims of the present study was to enable us to estimate the magnitude of effects that would be detectable in experimental manipulations of the fauna in Botany Bay.

While the present study has concentrated on the distribution of macrofauna, other sediment-related variables, such as pollutants, are likely to show similar variation. Nested designs are therefore appropriate to sampling these variables. Correlation among scales of patchiness between different variables can then be examined. These may suggest causal relationships, or associations with common covariables

Finally, it is important to note that the spatial patterns identified in this study are likely to change with time. Interactive effects of space and time are probable; there is no reason to presume that temporal trajectories of mean abundance will be exactly the same for all scales of distribution of the organisms. Short-term temporal variation will have similar effects of confounding or reduction of power on longer-term comparisons to the small-scale spatial variation considered above (Underwood 1991a, b).

In conclusion, much more care is needed in the identification of appropriate spatial scales for sampling before conclusions are reached about differences in abundances of organisms from one place to another in soft sediments. Although this is supposedly widely known, few studies demonstrate that appropriate sampling has been done to unconfound the effects of smaller-scale spatial differences when larger-scale comparisons are made 
Acknowledgements. We thank G. Inglis, S. McCune and J. Miller for help in collecting and sorting samples, and K. Astles for help with everything, especially computing. This study was supported by an ARC grant (to A.J.U.) and funds from the Institute of Marine Ecology and the Research Grant of the University of Sydney.

\section{LITERATURE CITED}

Andrew, N. L., Mapstone, B. D. (1987). Sampling and the description of spatial pattern in marine ecology. Oceanogr. mar. Biol. Ann. Rev 25: 39-90

Barry, J. P., Dayton, P. K. (1991). Physical heterogeneity and the organization of marine communities. In: Kolasa, J, Pickett, S. T. A. (eds.) Ecological heterogeneity. SpringerVerlag, New York, p. 270-320

Botton, M. L. (1979). Effects of sewage sludge on the benthic invertebrate community of the inshore New York Bight. Estuar. coast. Shelf Sci. 8: 169-180

Buchanan, J. B., Kingston, P. F., Sheader, M. (1974). Longterm population trends of the benthic macrofauna in the offshore mud of the Northumberland coast. J mar. biol. Ass. U.K. 54: 785-795

Buchanan, J. B., Moore, J. J. (1986). A broad review of variability and persistence in the Northumberland benthic fauna-1971-85. J. mar. biol. Ass. U.K. 66: 641-657

Buchanan, J. B., Sheader, M., Kingston, P. F. (1978). Sources of variability in the benthic macrofauna off the south Northumberland coast, 1971-1976. J. mar. biol. Ass. U.K. 58: 191-209

Butman, C. A. (1987). Larval settlement of soft-sediment invertebrates: the spatial scales of pattern explained by active habitat selection and the emerging role of hydrodynamical processes. Oceanogr. mar. Biol. Ann. Rev. 25: $113-165$

Duineveld, G. C. A., de Wilde, P. A. W. J., Kok, A. (1990). A synopsis of the macrobenthic assemblages and benthic ETS activity in the Dutch sector of the North Sea. Neth. J. Sea Res. 26: 125-138

Eleftheriou, A., Basford, D. J. (1989). The macrobenthic infauna of the offshore southern North Sea. J. mar. biol. Ass. U.K. 69: 123-143

Elliott, J. M. (1977). Some methods for the statistical analysis of samples of benthic invertebrates, 2nd edn. Freshwater Biological Association, Ambleside

Gray, J, S. (1974). Animal-sediment relationships. Oceanogr. mar. Biol. Ann. Rev. 12: 223-261

Green, R. H. (1979). Sampling design and statistical methods for environmental biologists. Wiley, Chichester

Green, R. H., Hobson, K. D. (1970). Spatial and temporal structure in a temperate intertidal community, with special emphasis on Gemma gernma (Pelecypoda: Mollusca). Ecology 51: 999-1011

Hornung, H., Krom, M. D., Cohen, Y. (1989). Trace metal distribution in sediments and benthic fauna of Haifa Bay, Israel. Estuar. coast. Shelf Sci. 29: 43-56

Hurlbert, S. H. (1984). Pseudoreplication and the design of ecological field experiments. Ecol. Monogr. 54: 187-211

Jones, G. P., Ferrell, D. J., Sale, P. F. (1990). Spatial pattern in the abundance and structure of mollusc populations in the soft sediments of a coral reef lagoon. Mar. Ecol. Prog. Ser. 62: $109-120$

Josefson, A. B. (1987). Large-scale patterns of dynamics in subtidal macrozoobenthic assemblages in the Skagerrak: effects of a production-related factor? Mar. Ecol. Prog. Ser. 38: $13-23$
Jumars, P. A., Thistle, D., Jones, M. L. (1977). Detecting twodimensional spatial structure in biological data. Oecologia (Berl.) 28: 109-123

Kennelly, S. J., Underwood, A. J. (1984). Underwater microscope sampling of a sublittoral kelp community. J. exp. mar. Biol. Ecol. 76: 67-78

Kennelly, S. J., Underwood, A. J. (1985). Sampling of small invertebrates on natural hard substrata in a sublittoral kelp forest. J. exp. mar. Biol. Ecol. 89: 55-67

Krumgalz, B. S., Fainshtein, G., Sahler, M., Gorfunkel, L. (1989). 'Field error' related to marine sediment contamination studies. Mar. Pollut. Bull. 20:64-69

Larsen, P. F. (1979). The shallow-water macrobenthos of a northern New England estuary. Mar. Biol. 55: 69-78

Luoma, S. N., Phillips, D. J. H. (1988). Distribution, variability, and impacts of trace elements in San Francisco Bay. Mar. Pollut. Bull. 19: 413-425

McArdle, B. H., Blackwell, R. G. (1989). Measurement of density variability in the bivalve Chione stutchburyi using spatial autocorrelation. Mar. Ecol. Prog. Ser. 52: 245-252

McIntosh, R. P. (1991). Concept and terminology of homogeneity and heterogeneity in ecology. In: Kolasa, J., Pickett, S. T. A. (eds.) Ecological heterogeneity. SpringerVerlag, New York, p. 24-46

Newell, R. C., Maughan, D. W., Trett, M. W., Newell, P. F., Seiderer, L. J. (1991). Modification of benthic community structure in response to acid-iron wastes discharge. Mar. Pollut. Bull. 22: 112-118

Pearson, T. H. (1975). The benthic ecology of Loch Linnhe and Loch Eil, a sea-loch system on the west coast of Scotland. IV. Changes in the benthic fauna attributable to organic enrichment. J. exp mar. Biol. Ecol. 20: 1-41

Phillips, F. E., Fleeger, J. W. (1985). Meiofauna meso-scale variability in two estuarine habitats. Estuar. coast. Shelf Sci. 21: 745-756

Probert, P. K. (1981). Changes in the benthic community of china clay waste deposits in Mevagissey Bay following a reduction of discharges. J. mar. biol. Ass. U.K. 61: 789-804

Shillabeer, N., Tapp, J. F. (1989). Improvements in the benthic fauna of the Tees Estuary after a period of reduced pollution loadings. Mar. Pollut. Bull. 20: 119-123

Snedecor, G. W., Cochran, W. G. (1967). Statistical methods, 6th edn. University of lowa Press

Stanley, D. J., Swift, D. J. P. (1976). Marine sediment transport and environmental management. Wiley, New York

Swartz, R. C., Cole, F. A., Schults, D. W., DeBen, W. A. (1986). Ecological changes in the southern California Bight near a large sewage outfall: benthic conditions in 1980 and 1983. Mar. Ecol. Prog. Ser. 31:1-13

Thorson, G. (1957). Bottom communities (sublittoral or shallow shelf). In: Hedgpeth, G. (ed.) Treatise on marine and palaeoecology, Vol. 1. Mem. Geol. Soc. Am., no. 67, p. 461-534

Thrush, S. F. (1986a). Spatial heterogeneity in subtidal gravel generated by the pit-digging activities of Cancer pagurus. Mar. Ecol. Prog. Ser. 30: 221-227

Thrush, S. F. (1986b). The sublittoral macrobenthic community structure of an Irish sea-lough: effect of decomposing accumulations of seaweed. J. exp. mar. Biol. Ecol. 96: $199-212$

Thrush, S. F. (1991). Spatial patterns in soft-bottom communities. TREE 6: 75-79

Thrush, S. F., Hewitt, J. E., Pridmore, R. D. (1989). Patterns in the spatial arrangements of polychaetes and bivalves in intertidal sandflats. Mar. Biol. 102: 529-535

Underwood, A. J. (1981). Techniques of analysis of variance in experimental marine biology and ecology. Oceanogr. mar. Biol. Ann. Rev. 19; 513-605 
Underwood, A. J. (1991a). Beyond BACI: experimental designs for detecting human environmental impacts on temporal variations in natural populations. Aust. J mar. Freshwat. Res. 42: 569-587

Underwood, A. J. (1991b). Spatial and temporal problems with monitoring. In: Calow, P., Petts, G. E. (eds.) Rivers handbook Vol. 2. Blackwell Scientific, Oxford (in press)

Underwood, A. J., Petraitis, P. S. (1991). Structure of intertidal assemblages in different locations: how can local pro-

This article was submitted to the editor cesses be compared. In: Ricklefs, R. E., Schluter, D. (eds.) Historical and geographical determinants of community diversity. University of Chicago Press (in press)

Volckaert, F. (1987). Spatial pattern of soft-bottom Polychaeta off Nova Scotia, Canada. Mar. Biol. 93: 627-639

Warwick, R. M., Davies, J. R. (1977). The distribution of sublittoral macrofauna communities in the Bristol Channel in relation to the substrate. Estuar. coast. Shelf Sci. 5: $267-288$

Manuscript first received: December 12, 1991

Revised version accepted: March 10, 1992 